\title{
Prereferral Process with Latino English Language Learners with Specific Learning Disabilities: Perceptions of English-as-a-Second-Language Teachers
}

\author{
Emily Ferlis \\ Virginia Commonwealth University \\ U. S. A. \\ Yaoying $\mathrm{Xu}$ \\ Virginia Commonwealth University \\ U. S. A.
}

ABSTRACT: This study explored perceptions of English-as-a-second-language (ESL) teachers on the prereferral process for Latino English language learners (ELLs). Using Colaizzi's (1978) phenomenological approach, qualitative data were collected through interviews with four ESL teachers. Analyses of the data indicated that the ESL teachers used research-based interventions and progress-monitoring in the prereferral process with Latino ELLS. Data analysis also indicated negative participant perceptions of parental and school-level influence on the identification process. Key concerns about the identification of Latino ELLs with specific learning disabilities (SLD) are presented, raising questions about current practices in school districts with small ELL populations.

KEYWORDS: English learners, prereferral, learning disabilities, teacher perception, Latino

\author{
Identification of Specific Learning Disabilities (SLD) \\ Theoretical Framework \\ Purpose of Study \\ Method \\ Results \\ Discussion and Implications \\ Conclusion \\ Notes \\ References \\ Author Contact
}

The number of English language learners (ELLS) has grown significantly in U.S. schools over the past decade, and this growth has been especially evident in areas with traditionally small or non-existent ELL populations (Orfield \& Frankenberg, 2014). The greatest population increase has been in the number of Spanish-speaking Latino ELLs. Among the over 460 languages that are represented in U.S. schools and programs (McEntire, 2014), Spanish is the first language of the vast majority of ELLs (Santos, 
2013). This is most likely due to the large growth in the number of Latino students in U.S. schools, which, according to Orfield and Frankenberg (2014), increased by $495 \%$ between 1968 and 2011. Of the more than five million ELLs in U.S. public schools, $75 \%$ are Spanish-speaking (Orosco \& O'Connor, 2014; Planty et al., 2009).

The growing population of Latino ELLS is facing major academic challenges. Latino students have the highest dropout rate in U.S. public schools (National Center for Education Statistics, 2014). Data from the 2009 National Assessment of Educational Progress (NAEP) show a 25-point gap between Caucasian students and Latino/as in fourth-grade reading achievement and a 24-point discrepancy at eighth grade (Hemphill \& Vanneman, 2010). ELLs who are at risk for reading failure or who have been placed in special education are often the lowest performing readers, in terms of decoding, word reading, and fluency (Swanson, Orosco, Lussier, Gerber, \& Guzman-Orth, 2011; Turkan \& Buzick, 2016). The majority of Latino ELLs with disabilities have specific learning disabilities (SLDs), with reading difficulties as the core problem (Orosco \& O'Connor, 2014; Zehler et al., 2003).

\section{Identification of Specific Learning Disabilities (SLDs)}

Although the number of ELLs and ELLs with SLDs has increased, the literature indicates that few teachers have received preparation or training in how to identify or support ELLs with SLDs (Kushner, 2008). Lack of training on second language acquisition (SLA) and ESL pedagogy has been correlated with inappropriate ELL identification practices (Colombo, McMakin, Jacobs, \& Shestok, 2013; Fletcher \& Navarrete, 2003; Orosco \& Klingner, 2010; Turkan \& Buzick, 2016). The appropriate identification of ELLs with special needs has been an ongoing challenge for U.S. schools, evidenced by decades of disproportionate ELL representation in special education programs (Abedi, 2008; Artiles \& Ortiz, 2002; Lane \& Leventhal, 2015). The historical debate over ELL representation patterns has been fueled by contradictory conclusions that Latino ELLs have been statistically both overrepresented (Artiles, Rueda, Salazar, \& Higareda, 2005) and underrepresented in special education categories (Zehler et al., 2003). The history of disproportionate ELL representation in special education programs was addressed in the 2004 reauthorization of the Individuals with Disabilities Education Act (IDEA, 2004), which acknowledged the "documented apparent discrepancies in the levels of referral and placement of limited English proficient children in special education" [20 U.S.C. \$1400(b)(1)]. IDEA 2004 continued to mandate procedures for identifying ELLs with SLDs, in addition to introducing the option of using research-based interventions in the process of identifying students with SLDs [20 U.S.C. 1414 (b)(6)]. IDEA 2004 allowed states to choose whether to use research-based interventions, such as response-to-intervention (RTI), in the prereferral process for identifying students with SLDs. ${ }^{1}$

The response-to-intervention (RTI) model is a research-based intervention approach that was designed to provide extensive contextual information on student ability and progress through the use of tiered interventions (Fuchs \& Fuchs, 2006). RTI was created to allow for the consideration of additional interpersonal and institutional 
factors that may impact student performance, as opposed to the IQ-discrepancy model, which utilized assessment systems to determine within-child deficits (Harris-Murri, King, \& Rostenberg, 2006). RTI was designed as a tiered approach for providing services and intervention for at-risk students through universal screening, the monitoring of progress over time, and the use of multiple assessment tools to dictate additional evidence-based instruction or additional interventions to address educational needs (Fuchs \& Fuchs, 2006). Students are first screened at the grade level and progress is assessed regularly so that interventions can be provided in a timely manner (Vaughn \& Fuchs, 2003). The prereferral intervention stages may include Tier 1 and Tier 2. Tier 1 consists of the classroom teacher monitoring student progress in response to research-based instruction in the general education classroom setting. If students do not respond to Tier 1, they are provided with Tier 2 support that involves monitoring student progress when provided with small-group, differentiated instruction with the teacher or with another instructor. Students who do not respond to Tier 2 qualify for Tier 3 intervention, which consists of further individualized support, and, if necessary, the student is referred for a comprehensive special education evaluation, followed by special education placement (Orosco \& Klingner, 2010). RTI is considered to be a prevention and intervention model (Vaughn \& Fletcher, 2012; Vaughn \& Fuchs, 2003) because it was designed to support progress for struggling learners with or without disabilities, provide individual and evidence-based intervention, and distinguish between students with SLDs and those who have received poor instruction (Hughes \& Dexter, 2011; Orosco \& Klingner, 2010).

At the time that IDEA 2004 was passed, there was very little research on the use of research-based interventions with ELLs. Conway, Christensen, Russell, and Brown (2000) had conducted a study of principals' perceptions of prereferral intervention with ELLs that indicated teachers were unwilling or unable to implement research-based intervention because they lacked the requisite training and resources. Donovan and Cross (2002) discussed that research-based intervention might be more appropriate than the IQ-discrepancy method used since 1977. Artiles and Ortiz (2002) suggested that the shift from IQ-discrepancy to research-based intervention might reduce disproportionate ELL representation. Both the USDOE Learning Disability Summit (Bradley, Danielson, \& Hallahan, 2002) and the President's Commission on Excellence in Special Education (2002) used evidence from researcher-implemented studies of RTI to recommend moving away from the IQ-discrepancy approach towards the monitoring of progress in response to evidence-based instruction. At that time, little guidance was provided on how teachers should implement RTI in the classroom setting, and many educators were confused about how to use RTI (Orosco \& Klingner, 2010). IDEA (2004) was also passed before any empirical research had been conducted on the use of research-based interventions, such as RTI, with ELLs (Orosco \& Klingner, 2010).

\section{Theoretical Framework}

This study was grounded in a social constructivist framework (Vygotsky, 1978), which is important for helping educators understand the ways culture and language affect learning (Villegas \& Lucas, 2002). Sociocultural theory views learning and 
development as culturally, historically, and socially mediated processes (Vygotsky, 1962, 1978). According to the Vygotskian perspective, learning and development are influenced by various interacting factors that occur within a larger cultural context. Cognition does not exist in the biological development alone, but is part of a larger environment that is impacted by resources, culture, and language. Sociocultural theory suggests that cultural and linguistic practices, as well as beliefs and values, affect the learning process of ELLs. Research on the impact of teacher knowledge on ELLs has further supported this theory. Studies have shown that effective instruction and assessment of ELLs requires educators to understand how culture, language, and prior experience affect student learning and outcomes (Baca \& Cervantes, 2004; Klingner \& Edwards, 2006; Orosco \& Klingner, 2010; Orosco \& O'Conner, 2014; Xu \& Drame, 2008).

Research on prereferral processes and impact on ELLs also points to the importance of teacher knowledge of ESL pedagogy and second language acquisition (SLA) (Klingner \& Edwards, 2006; Orosco \& Klingner, 2010; Xu \& Drame, 2007). Because instructional and assessment methods that are found effective with mainstream English-only students are not necessarily effective with ELLs, it is important that educators of ELLs use high-quality, evidence-based ESL strategies that have been validated with similar students and in similar contexts (Klingner \& Edwards, 2006). Teachers should also understand how learning to read in English as a second or additional language is both similar to and different from learning to read in one's first language (August \& Shanahan, 2006). Historically, educators tended to treat language acquisition as indicative of cognitive deficits and to blame students' poor performance on their lack of English proficiency (Cummins, 2000). Baca and Cervantes (2004) found that teacher misunderstanding of the language acquisition process has resulted in inappropriate identification of SLDs, while Orosco and Klingner (2010) found that RTI is ineffective with ELLs when implemented by teachers who do not understand ESL pedagogy, SLA, and the cultural and linguistic backgrounds of ELLs.

Sociocultural theory suggests that effective instruction and assessment requires educator knowledge of ESL pedagogy and SLA, as well as an understanding of how culture, language, beliefs, and values affect ELL learning and outcomes. This framework provided a lens that helped the researchers examine the ESL teachers' perspectives of the prereferral process with Latino ELLs and interpret the findings.

\section{Purpose of Study}

This study sought to address several gaps in the literature base related to prereferral impact on the identification of Latino ELLs with SLDs. This study was part of a larger dissertation study (Ferlis, 2012) that used the same conceptual framework but a different focus. First, the research was designed to focus on Latino ELLs with SLDs because Latino ELLs represent the majority of ELLs (Santos, 2013) and the fastestgrowing student population (Orfield \& Frankenberg, 2014). The low levels of academic achievement (Fry \& Lopez, 2012) and high rate of dropout (NCES, 2014) further necessitated the need to focus the study on Latino ELLs. Second, the study sought to 
address the perceptions of ESL teachers because of the absence of ESL teachers' voices in the existing literature and the evidence that ESL teachers may spend the most instructional time with ELLs and have the deepest understanding of policy impact on ELLs (Wright \& Choi, 2006). Third, the study was designed to examine the perceptions of teachers in a school district with a small percentage of ELLs because demographic data indicated that a growing number of ELL families are moving into school districts with traditionally small ELL populations (Capps et al., 2005). Since prior research has been limited to schools with large ELL populations (Greenfield, Rinaldi, Proctor, \& Cardarelli, 2010; Orosco \& Klingner, 2010), this study was designed to address the gap. Finally, because of the impact of culture and language on the effect of prereferral processes with ELLs (Klingner \& Edwards, 2006; Orosco \& Klingner, 2010; Xu \& Drame, 2008), the study was designed to add to the limited existing research framed by the social constructivist approach. The current research was guided by the following questions:

1. What are the prereferral processes used by elementary and middle school ESL teachers in a rural school district with a small ELL population to identify Latino ELLs with suspected SLDs?

2. Do ESL teachers in rural school districts with small ELL populations use research-based interventions, such as RTI, in the prereferral process for identifying Latino ELLs with suspected SLDs? If so, how is RTI implemented with ELLs? If not, what are the reasons that ESL teachers do not use RTI in the prereferral process with ELLs?

3. In a rural school district with a small ELL population, what are elementary and middle school ESL teachers' perceptions of the current prereferral process for ELL identification of SLDs? Do these ESL teachers experience challenges during the prereferral process? If so, what are they?

\section{Method}

The strategy of inquiry for this study was a qualitative, phenomenological approach (Colaizzi, 1978; Smith, Flowers, \& Larkin, 2009). This approach is appropriate for research that seeks to understand common or shared experiences to develop practices or policies, or to develop a deeper understanding of the features of the phenomenon (Creswell, 2007). There is a need for qualitative, descriptive research that increases understanding of how school personnel feel about the implementation and challenges of research-based intervention with ELLs (Orosco \& Klingner, 2010). By using a phenomenological approach, the researchers were able to develop an in-depth description of the "essence" of the prereferral process experienced by the school district's ESL teachers. 


\section{Setting and Participants}

Table 1

Demographic information of participants

\begin{tabular}{|c|c|c|c|c|c|c|c|}
\hline Participant & $\begin{array}{l}\text { Current } \\
\text { Teaching } \\
\text { Position }\end{array}$ & $\begin{array}{l}\text { Teaching } \\
\text { experience } \\
\text { (\# years) }\end{array}$ & $\begin{array}{l}\text { Education } \\
\text { background }\end{array}$ & $\begin{array}{c}\text { ELL } \\
\text { identification } \\
\text { coursework/PD }\end{array}$ & $\begin{array}{c}\text { Type of } \\
\text { ESL } \\
\text { Instruction }\end{array}$ & $\begin{array}{l}\text { Total \# } \\
\text { ELLs in } \\
\text { current } \\
\text { classes }\end{array}$ & $\begin{array}{c}\text { Total } \\
\# \\
\text { Latino } \\
\text { ELLs }\end{array}$ \\
\hline Ms. A & $\begin{array}{c}\text { Elementary } \\
\text { school ESL } \\
\text { teacher, } \\
\text { grades k-5 }\end{array}$ & 4 & $\begin{array}{l}\text { Master's } \\
\text { degree, k- } \\
12 \mathrm{ESL} \\
\text { teaching } \\
\text { certification }\end{array}$ & $\begin{array}{c}2 \text { day-long } \\
\text { general special } \\
\text { education PD } \\
\text { workshops }\end{array}$ & Pull-out & 20 & 8 \\
\hline Ms. B & $\begin{array}{c}\text { Elementary } \\
\text { school ESL } \\
\text { teacher, } \\
\text { grades k-5 }\end{array}$ & 6 & $\begin{array}{l}\text { Master's } \\
\text { degree, k- } \\
12 \mathrm{ESL} \\
\text { teaching } \\
\text { certification }\end{array}$ & 0 & Pull-out & 18 & 9 \\
\hline Ms. C & $\begin{array}{c}\text { Middle and } \\
\text { high school } \\
\text { ESL } \\
\text { teacher, } \\
\text { grades 6-8, } \\
9-12\end{array}$ & 5 & $\begin{array}{c}\text { Master's } \\
\text { degree, k- } \\
12 \\
\text { Spanish \& } \\
\text { ESL } \\
\text { teaching } \\
\text { certification }\end{array}$ & $\begin{array}{l}1 \text { graduate- } \\
\text { level general } \\
\text { special } \\
\text { education } \\
\text { course, } 1 \text { day- } \\
\text { long general } \\
\text { special } \\
\text { education PD } \\
\text { workshop }\end{array}$ & $\begin{array}{l}\text { Sheltered } \\
\text { Instruction }\end{array}$ & 25 & 7 \\
\hline Ms. D & $\begin{array}{c}\text { Middle and } \\
\text { high school } \\
\text { teacher, } \\
\text { grades 6-8, } \\
9-12\end{array}$ & 20 & $\begin{array}{c}\text { Master's } \\
\text { degree, k- } \\
12 \\
\text { Spanish \& } \\
\text { ESL } \\
\text { teaching } \\
\text { certification }\end{array}$ & 0 & $\begin{array}{l}\text { Sheltered } \\
\text { Instruction }\end{array}$ & 23 & 17 \\
\hline
\end{tabular}

Woodsville County Public Schools (WCPS, pseudonym) is a rural school district in central Virginia that includes 15 elementary schools, 4 middle schools, and 4 high schools. During academic year 2014-2015, WCPS served 18,041 students in kindergarten through grade 12 , of whom $81 \%$ were Caucasian, $8 \%$ were African American or Asian, and 3\% were Latino. Twenty-one percent, or 3,790 students, were included in the special education child count in 2013. Less than one percent of students were categorized as meeting the state's English language proficiency test publisher definition of English language learners. Of the 119 students categorized as ELLs, 46\% 
or 55 were Latino ELLs. WCPS functioned as an ESL immersion program that provided pull-out services for elementary-level ELLs and in-class ESL services for secondarylevel ELLS.

Four of the six full-time ESL teachers in WCPS agreed to participate in this study. The participants included two elementary-level ESL teachers and two secondary-level ESL teachers who taught both middle and high school ESL classes (Table 1). Each of the participants had a master's degree in education with a state endorsement to teach ESL. The two secondary-level teachers also had a state endorsement to teach Spanish. All of the four participants were Caucasian women. The participants' experience teaching ESL ranged from 4 to 20 years. Latino ELLs comprised approximately $48 \%$ of the ELL students whom the teachers instructed.

\section{Data Collection and Analysis}

The six full-time ESL teachers in the school district were contacted through email and invited to participate in a larger dissertation study of two school districts. Four teachers agreed to participate after reading the consent agreement and giving informed consent. Each participant agreed to allow the interviewers to audiotape the interview. Consent was obtained prior to any data collection, and the first author conducted the individual, face-to-face interviews with the participants. Each interview lasted between 90 and 170 minutes. During each interview, the first author took notes and wrote analytic memos. The interview protocol was guided by a set of 18 predetermined questions. ${ }^{2}$ These questions were initially generated from the literature and then further refined through expert review and peer feedback. Interview questions included, "What do you feel are the most effective practices for supporting low-performing Latino ELLs with suspected learning disabilities?" and "How do you work with other educators to provide support or assessment of struggling ELLs?" The researcher also asked followup questions during the interviews to prompt deeper discussion of specific topics (Creswell, 2007). The follow-up questions prompted participants to provide more information about their experiences and perceptions of the prereferral processes used to identify Latino ELLs with SLDs (total of 49 transcribed pages). Each participant was assigned a code number to maintain confidentiality, and all identifying information was removed from the data. To increase validity, respondent verification and member checking were used. Institutional Review Board (IRB) approval was obtained from the university and the school division. Consents were obtained from participants prior to data collection.

The first author conducted initial data analysis following Colaizzi's (1978) phenomenological method (Figure 1). 


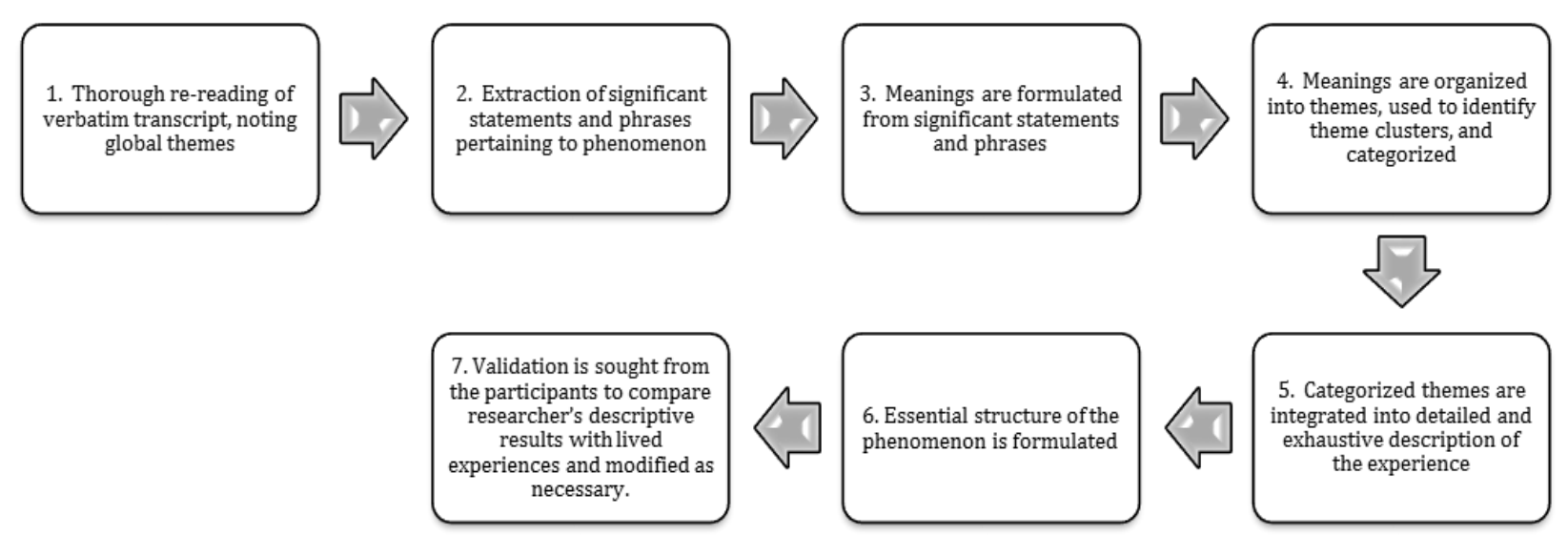

Figure 1. Colaizzi's (1978) Phenomenological Method

The audiotaped interviews were transcribed following this approach, and the written transcripts were read several times to obtain a sense of the participants' experiences and perceptions. From each transcript, significant phrases or sentences that provided an understanding of how the participants experienced the phenomenon were identified (Creswell, 2007). The significant phrases were used to develop clusters of meaning, which were formulated into emergent themes. Transcribed data were triangulated with interviewer notes and analytical memos. The significant statements and themes were used to write a "textual description" of what the participants experienced, as well as a "structural description" of the context or setting that influenced how the participants experienced the phenomenon (Creswell, 2007, p. 61). A composite report of the shared participant viewpoints and experiences was compiled from the textural and structural descriptions and verbatim examples, resulting in an in-depth description of the ESL teachers' perceptions of the prereferral process for Latino ELLS.

To ensure the credibility of the data, we employed several measures recommended for qualitative research including member checks, confirming/ disconfirming evidence, and theory triangulation (Brantlinger, Jimenez, Klingner, Pugach, \& Richardson, 2005). Through member checks, we had participants review and confirm the accuracy of interview transcriptions prior to analyses and interpretations of the results. The confirming/disconfirming evidence was obtained through a process in which the researchers examined the preliminary themes and categories that had been established through initial reviews and looked for evidence that was inconsistent with the themes. The theory triangulation allowed us to search for convergence of evidence from multiple perspectives to interpret a single set of data through a comparison between participants' perspectives with researcher notes and analytical memos. 


\section{Results}

The ESL teachers' perceptions are presented using a thematic approach. Three overarching themes emerged from the three research questions: Intervention use, perceived parental resistance, and school-level barriers.

\section{Intervention Use}

In all interviews, teachers reported using research-based interventions in the prereferral process with Latino ELLs. As mentioned earlier, the prereferral intervention stages may include tiered-instruction in general education settings prior to a formal referral for comprehensive special education evaluations. One essential component of the RTI model was progress monitoring that examined students' response (or nonresponse) to research-based instruction in the general education classroom setting (Orosco \& Klingner, 2010). While only one teacher reported formally using the RTI approach, all of the teachers described the use of prereferral intervention strategies that aligned with the RTI model within and across tiers. These included progress-monitoring using curriculum-based or teacher-designed measures, small-group intervention, and one-on-one tutoring during the prereferral process with ELLS. All of the teachers described the use of an informal process of monitoring the progress of struggling ELLs that they found to be effective in identifying ELLs with SLDs. For example, one teacher said:

I use the sight words. It's a list of sight words and there are four or five different ones. At the beginning of the year, I will test them to see which ones they know or don't know. And, I will do that again in January. But, if someone that I think may need a child study, I will repeat it sooner. So that's one thing. We didn't have anything formal...we didn't have that response-to-intervention or anything. So, I will just keep a folder with all of their comprehension exercises or just jot down notes.

The teachers reported using both small-group and individual interventions based upon data collected through the informal progress-monitoring process. All of the teachers found individualized interventions more effective in identifying ELLs with SLDs than small-group interventions because "they get distracted in the group" and "they will start speaking Spanish together." When asked about the use of RTI, teachers responded that they felt that it "slowed down the identification process with ELLs." Another teacher said that:

I think it is a slower process, RTI with ELLs versus regular kids, because the teachers already know what to do with regular kids. If they are having this problem, you do this. They are used to that. But with ELLs, it is scary for a teacher. They are like, "I don't understand.... just don't know why they are doing this!" And sometimes the ELL is so significantly below level, because of their 
language barrier. So, I have that struggle with it, with RTI. That it slows things down.

The descriptions of intervention use, progress-monitoring, and tutoring during the prereferral process were consistent throughout these collected data. Although instructors did not report the use of RTI, with the exception of one participant, all participants reported the use of methods and approaches that were aligned with the RTI model.

\section{Perceived Parental Resistance}

An additional theme that emerged from these data was that the ESL teachers who participated in this study perceived parents as resistant to the prereferral process. The ESL teachers communicated that they felt parents were resistant for two reasons: discomfort in the school environment and concern over a cultural "stigma" concerning disability. One participant stated that "the parents didn't want to go to the school or go anywhere official." According to another participant, "They didn't want to have anything to do with the necessary policies." The teachers believed that the parents were "afraid of being deported" or "scared that it would be assumed they were illegal." In addition, the teachers felt that Latino ELL parents did not want to participate in the prereferral process because of negative cultural stigma related to disability. They reported believing that parents of ELLS with SLDs "come here because they have kids with learning disabilities who don't get support in their country" or because "it might just be unacceptable in their culture." Several participants felt that Latino ELL parents did not disclose information about SLDs because it was "not a priority to tell the school" or because "they don't want anyone to identify them as having a problem." All of the teachers expressed that they felt that Latino ELLs with SLDs were under-identified because of lack of parental input or participation. One teacher stated that:

With Spanish-speakers, I would say there is under-identification. And I think that is culturally, well, that they view learning disabilities with more of a stigma than Americans. Like, sometimes I feel Americans view it as a badge of honor to have special accommodations. When I taught Spanish, kids would be like "I have an IEP....I shouldn't have to do this." It is the parents too. The American parents would be like, "I just know my kid has a disability." They would keep at it and just be more pushy. But then in ESL, you don't have the parents pushing to get them labeled. So, overall, I think there is under-identification.

The theme of parental resistance to the prereferral process was common throughout collected data. It was referenced throughout interviews as a significant barrier in the process of identifying Latino ELLs with SLDs. 


\section{School-Level Barriers}

Although the participants classified parental resistance as a barrier to identification, the most common theme throughout the data was the school-level barriers to the prereferral process with Latino ELLs. Each teacher described having to "fight to get a child identified" because special education departments or other school personnel resisted or refused ELL identification. The teachers reported feeling pressured not to refer ELLs. When the teachers attempted to provide evidence of ELL progress-monitoring to the special education departments, they reported being told to wait and "give them more time" because of language barriers. One teacher said that "the special ed teachers and administrators, especially in a county without a really large percentage of ELLs, don't know how to handle it so there is this automatic assumption that it is a language issue." Both the elementary and secondary-level teachers described the negative impact of this approach on the students. Ms. A described how an ELL with autism was not identified until third grade because "everyone kept saying it is language, it is language." The same teacher stated that:

I'm told to wait because they read the information that it takes 5 to 7 years for an ELL to become proficient in academic language. So they say it is a language issue. So that would seem to me to be a paradox because you need to wait a time to acquire the language, but you don't have 5 to 7 years to wait to provide the services to a kid who comes in during high school and gets frustrated. Or even for a 6 th or 7 th grader. To identify the problem when they are a junior in high school? That's too late.

The participants also described school-level resistance to using native-language assessments with ELLs for identification purposes. Three of the four teachers reported that their school refused to give native-language assessments to ELLs. Native-language assessment was described as "not even put on the table to discuss because of cost" and "just not an option." One participant stated that:

I asked because I had read somewhere that you have to try to provide a person an assessment in their own language. So, I was trying to pursue this, I just kept pushing about it, and they just kept telling me "no." The administration, the school did.

The teachers described concern over the validity of the assessments given to ELLs. For example, one teacher said that:

They gave her a test. They gave her all the tests and they said she's just not scoring high enough on any of the tests to show a disparity, so she doesn't have a learning disability, and she didn't score low enough on the tests to have MR. And the tests were in English.

The participants also described being excluded from the prereferral and referral process with ELLs. Several of the teachers talked about how the special education department 
did not communicate with them or include them in meetings. Another described her reaction to finding out that she had been excluded from an ELL referral meeting, stating:

In fact, he was referred and found ineligible...because of language. And without an ESL person present. So, then, I came in and said, "What in the world?"

The teachers expressed frustration and anger over the lack of school-level support. One teacher said that "the biggest frustration for me is that, in a county where you don't have that many ELLs, you struggle with the fact that students are not receiving services...unless you have an IEP, you don't get any help and it is wrong and it makes me really mad." Another teacher described feeling that "because there aren't enough ELLs to be a subgroup it is not important to them." All of the teachers reported that they felt that teachers and administrators did not understand SLA or how to teach ELLs. They expressed that they felt professional development was needed, but that it was not a priority because of the small ELL population.

\section{Discussion}

This study described ESL teachers' perceptions of the prereferral process for identifying Latino ELLs with SLDs in one school district with a small ELL population. The findings indicated that the participants did apply use of research-based interventions and progress-monitoring but perceived the impact as ineffective due to parental resistance and school-level barriers.

Research-based intervention was recommended as an improvement over the IQdiscrepancy method with ELLs (Donovan \& Cross, 2002), and our findings suggest that the ESL teachers who participated in this study viewed this approach as an appropriate practice for identifying ELLs with SLDs. The success of research-based intervention is dependent on several factors that are practiced by teachers and institutions, such as attitudes, beliefs, assessment and instructional methods, professional development opportunities, curriculum, and resources (Orosco \& Klingner, 2010). In addition, the research base indicates that successful implementation of RTI is multifaceted, also involving understanding of evidence-based interventions, multitiered intervention models, screening, assessment, progress monitoring, and coordinated efforts across all levels of staff and leadership within a school (Kratochwill, Volpiansky, Clements, \& Ball, 2007). Although the ESL teachers who participated in this study had knowledge of ESL pedagogy, SLA, and culturally and linguistically diverse students, and described the effectiveness of research-based intervention with ELLS, they viewed the prereferral process as ineffective because they felt other school personnel did not understand ELLs, while also viewing Latino ELL parents as resistant to participating in the process. Parental communication is an important factor in providing appropriate services for ELLs with SLDs. This finding supports Langdon's (2009) conclusion that teachers are faced with significant challenges in communicating the value of special education identification with Latino ELL parents. The findings also support the suggestion that Latino ELL parents may not want their children being identified with SLDs because they 
believe that students with disabilities will experience prejudice and ill-treatment by the school system (Langdon, 2009).

The data from this study indicated that ESL teachers viewed outreach as an important and successful factor with Latino ELLs, yet did not reference approaches to involve parents and ELL families. Outreach was described as an effective approach to increase ELL student motivation, as well as a strategy to employ in order to gain information and support in the prereferral process. While outreach was referenced as a useful method for student involvement and school-level support, there was little mention of strategies to increase Latino ELL family participation. This is significant, especially given the participants' views of parental resistance to involvement. While the participants spoke about how they "send information home in Spanish," there was no acknowledgement of reasons why this approach may be ineffective, other than fear of school participation and disability identification.

The findings from this study also suggest that the participants felt additional professional development in the area of ELL assessment and identification to be needed. One topic that emerges from the data is the need to focus professional development on differentiating between learning disability and typical language acquisition. The ESL teachers who participated in this study conveyed a perception that ineffective ELL identification was related to the inadequate training that special education teachers, general education teachers, and school administrators had received on working with ELLs. This perception is supported by prior research on ELLs with SLDs, which has shown that gaps in educator knowledge of ELLs correlate with disproportionate patterns of ELL identification of SLDs (Artiles \& Ortiz, 2002). The participants also discussed how their schools refused to provide native-language assessment of ELLs because of the additional cost of purchasing tests and compensating test administrators. The teachers described how their efforts to have ELLs provided with native-language assessments were refused by school administration and other school personnel. Three of the four participants reported never having a native-language assessment provided to an ELL, and all participants discussed their perception that invalid assessments in English were used with ELLs.

The literature has shown that English assessments are not valid measures of ELL ability and result in disproportionate ELL representation in special education categories (Donovan \& Cross, 2002; Harris-Murri et al., 2006). The participants felt that their schools continued to use invalid assessments in English because they felt the small ELL population did not warrant the additional cost and because resistance to parental participation resulted in a lack of advocacy for appropriate identification of Latino ELLs with SLDs. The research base has pointed to the importance of access to native-language assessments for ELLs, the active involvement of ELL parents, the inclusion of ESL teachers in the prereferral and referral processes, and professional development in ESL pedagogy, SLA, and ELL assessment. More research in this area is needed, in school districts with both large and small ELL populations. 


\section{Conclusion}

This study suggests that more research on the topic of ELL identification procedures is needed, and points to perceived challenges in school districts with small ELL populations. The data indicated that, while research-based interventions and progress monitoring were used by the ESL teachers in this study, participants felt that the current process was ineffective. Although the participants described the use of socioculturally-guided instruction and assessment with ELLs, the data indicated that they also felt the approach would not be successful without professional development for other stakeholders, including general and special educators and school administrators. The level of professional development received by these stakeholders is unknown, and future research should examine their perceptions of the process. The ESL teachers in this study reported feeling that the prereferral process did not result in appropriate identification because of school-level resistance and parental fear of participation, instead reporting that they felt Latino ELLs with SLDs were underidentified in their school district with a small ELL population. This finding does indicate a potential shift, at least in ESL teachers' perceptions, from overrepresentation of ELLs in special education to underrepresentation. It is important to note that it is unknown to what extent the participants have collaborated to build relationships with the Latino parents of students in this study and how immersed they are in the Latino culture in the community of this rural town. Such data should be included in future research.

There are several limitations to this study that must be addressed. The nature of this study was to provide an examination of the experiences of a small and homogenous group of ESL teachers, and it is important to note that these findings are not generalizable. Because this study focused only on ESL teachers' perspectives, the views of Latino parents, special education teachers, general education teachers, and school administrators are unknown. Additionally, the findings should be interpreted with caution as the data were limited to one school district in one state.

More research should be conducted with a larger sample of ESL teachers, as well as with special education teachers, school administrators, and Latino ELL families, to further examine the use of prereferral processes with Latino ELLs. While it is not known whether research-based interventions will reduce disproportionate Latino ELL representation in special education categories, the findings presented in this study indicate that some ESL teachers view the current process as ineffective and inequitable for Latino ELLs with suspected SLDs, and that continued work is needed in this area.

\section{Notes}

1. Despite the inconsistency of the definitions on research-based interventions, we follow the recommendations by Odom et al. (2005) and interpret the term as 
interventions or instructions that are informed by research with empirical data that have a direct relationship with the practices.

2. The interview protocol is available upon request by emailing the first author: ferlisec@vcu.edu

\section{References}

Abedi, J. (2008). Classification system for English language learners: Issues and recommendations. Educational Measurement: Issues and Practice, 27(3), 17-31.

August, D., \& Shanahan, T. (2006). Developing literacy in second-language learners: Report of the National Literacy Panel on language-minority children and youth. Mahwah, NJ: Lawrence Erlbaum.

Artiles, A. J., \& Ortiz, A. A. (Eds.). (2002). English language learners with special education needs: Identification, assessment, and instruction. Washington, DC: Center for Applied Linguistics and Delta Systems.

Artiles, A. J., Rueda, R., Salazar, J. J., \& Higareda, I. (2005). Within-group diversity in minority disproportionate representation: English language learners in urban school districts. Exceptional Children, 71, 283-300.

Baca, L. M., \& Cervantes, H. T. (Eds.). (2004). The bilingual special education interface. Upper Saddle River, NJ: Merrill/Prentice Hall.

Bradley, R., Danielson, L., \& Hallahan, D. (2002). Identification of learning disabilities: Research to practice. Mahwah, NJ: Lawrence Erlbaum.

Brantlinger, E., Jimenez, R., Klingner, J., Pugach, M., \& Richardson, V. (2005). Qualitative studies in special education. Exceptional Children, 71(2), 195-207.

Capps, R., Fix, M., Murray, J., Ost, J., Passel, J. S., \& Herwantoro, S. (2005). The new demography of America's schools: Immigration and the No Child Left Behind Act. Washington, DC: The Urban Institute.

Colaizzi, P. F. (1978). Psychological research as the phenomenologist views it. In R. Vaile \& M. King (Eds.), Existential phenomenological alternatives for psychology (pp. 48-71). New York, NY: Oxford University Press.

Colombo, M., McMakin, D., Jacobs, C., Shestok, C. (2013). Hopefulness for teachers of ELLs in the Era of NCLB. Multicultural Perspectives, 15(2), 81-87.

Conway, D. F., Christensen, J. E., Russell, J. F., \& Brown, J. D. (2000). Principals' perceptions of pre-referral student assistance teams. Educational Research Service Spectrum, 18(1), 14-19.

Creswell, J. W. (2007). Qualitative inquiry and research design: Choosing among five approaches. Thousand Oaks, CA: Sage Publications. 
Cummins, J. (2000). Pedagogies for the poor? Realigning reading instruction for lowincome students with scientifically-based reading research. Educational Researcher, 36(9), 564-572.

Donovan, S., \& Cross, C. (2002). Minority students in special and gifted education. Washington, DC: National Academic Press.

Ferlis, E. C. (2012). ESL Teachers' perceptions of the process for identifying adolescent Latino English language learners with specific learning disabilities. Retrieved from http://scholarscompass.vcu.edu/etd/2666/

Fletcher, T. V., \& Navarrete, L. A. (2003). Learning disabilities or difference: A critical look at issues associated with the misidentification and placement of Hispanic students in special education programs. Rural Special Education Quarterly, 22(4), 37-46.

Fry, R., \& Lopez, M. H. (2012). Hispanic student enrollment reach new highs in 2011. Washington, DC: Pew Hispanic Center. Retrieved from http://www.pewhispanic.org/2012/08/20/hispanic-student-enrollments-reach-newhighs-in-2011/

Fuchs, D., \& Fuchs, L. S. (2006). Introduction to Response to Intervention: What, why, and how valid is it? Reading Research Quarterly, 41(1), 93-99.

Greenfield, R., Rinaldi, C., Proctor, C. P., \& Cardarelli, A. (2010). Teachers' perceptions of a Response to Intervention (RTI) reform effort in an urban elementary school: A consensual qualitative analysis. Journal of Disability Policy Studies, 21(1), 4763.

Harris-Murri, N., King, K., \& Rostenberg, D. (2006). Reducing disproportionate minority representation in special education programs for students with emotional disturbances: Toward a culturally responsive response to intervention model. Education and Treatment of Children, 29(4), 779-799.

Hemphill, F. C., \& Vanneman, A. (2010). Achievement gaps: How Hispanic and White students in public schools perform in mathematics and reading on the National Assessment of Educational Progress (NCES 2011-459). Washington, DC: National Center for Education Statistics, Institute of Education Sciences, U.S. Department of Education.

Hughes, C. A., \& Dexter, D. D. (2011). Response to intervention: A research-based summary. Theory into Practice, 50, 4-11.

Individuals with Disabilities Education Act Amendments of 1997, Pub. L. No 94-142, 89 Stat. 773 (as amended), renamed IDEA, Pub. L. No 101-476, 104 Stat. 1143 [codified as amended at 20 U.S.C. § 1400 et seq.] (1994), amended by the IDEA Amendments of 1997, Pub. L. No. 105-17.

Individuals with Disabilities Education Act of 1990, Pub. L. 102-119, 20 U.S.C. § 1400 et seq. Individuals with Disabilities Education Improvement Act of 2004, 20 U.S.C. § 1400 et seq. 
Klingner, J. K., \& Edwards, P. (2006). Cultural considerations with response to intervention models. Reading Research Quarterly, 41, 108-117.

Kratochwill, T. R., Volpiansky, P., Clements, M., \& Ball, C. (2007). Professional development in implementing and sustaining multitier prevention models: Implications for response to intervention. School Psychology Review, 36(4), 618631.

Kushner, M. (2008). Preparing highly qualified teachers for English language learners with disabilities and at risk of disabilities. Multiple Voices for Ethnically Diverse Exceptional Learners, 11(1), 42-57.

Lane, S., \& Leventhal, B. (2015). Psychometric challenges in assessing English language learners and students with disabilities. Review of Research in Education, 39, 165-214.

Langdon, H. W. (2009). Providing optimal special education services to Hispanic children and their families. Communication Disorders Quarterly, 30(2), 83-96.

McEntire, N. (2014). ECAP Report: Working with preschool children who are English language learners. Childhood Education, 90(2), 172-173.

National Center for Education Statistics. (2014). Digest of Education Statistics: 2012 (NCES 2014-015). Washington, DC: U.S. Department of Education, Institute of Education Sciences.

Odom, S. L., Brantlinger, E., Gersten, R., Horner, R. H., Thompson, B., \& Harris, K. R. (2005). Research in special education: Scientific methods and evidence-based practices. Exceptional Children, 71(2), 137-148.

Orfield, G., \& Frankenberg, E. (2014). Brown at 60. Great progress, a long retreat, and an uncertain future. Los Angeles, CA: Civil Rights Project/Proyecto Derechos Civiles at UCLA.

Orosco, M. J., \& Klingner, J. (2010). One school's implementation of RTI with English language learners: "Referring into RTI." Journal of Learning Disabilities, 43(3), 269-288.

Orosco, M. J., \& O'Connor, R. (2014). Culturally responsive instruction for English language learners with learning disabilities. Journal of Learning Disabilities, 47(6), 515-531.

Planty, M., Hussar, W., Snyder, T., Kena, G., KewalRamani, A., Kemp, J., \& Dinkes, R. (2009). The condition of education 2009 (NCES 2009-081). Washington, DC: U.S. Department of Education, Institute of Education Sciences, National Center for Education Statistics.

President's Commission on Excellence in Special Education. (2002). A new era: Revitalizing special education for children and their families. Washington, DC: U.S. Department of Education.

Santos, R. M. (2013). Screening and evaluating children who are dual language learners: What every teacher should know. Retrieved from http://illinoisearlylearning.org/blogs/ell/rs-eval2lang.htm 
Smith, J. A., Flowers, P., \& Larkin, M. (2009). Interpretative phenomenological analysis: Theory, method, and research. London, UK: Sage.

Swanson, H. L., Orosco, M. J., Lussier, C. M., Gerber, M. M., \& Guzman-Orth, D. A. (2011). The influence of working memory and phonological processing on English language learner children's bilingual reading and language acquisition. Journal of Educational Psychology, 103(4), 838-856.

Turkan, S., \& Buzick, H. M. (2016). Complexities and issues to consider in the evaluation of content teachers of English language learners. Urban Education, 51(2), 221-248.

Vaughn, S., \& Fletcher, J. M. (2012). Response to intervention with secondary school students with reading difficulties. Journal of Learning Disabilities, 45(3), 244-256.

Vaughn, S., \& Fuchs, L. (2003). Redefining learning disabilities as inadequate response to instruction: The promise and potential problems. Learning Disabilities Research \& Practice, 18(3), 137-146.

Villegas, A. M., \& Lucas, T. (2002). Preparing culturally responsive teachers: Rethinking the curriculum. Journal of Teacher Education, 53(20), 20-32.

Vygotsky, L. S. (1962). Thought and language. Cambridge, MA: MIT Press.

Vygotsky, L. S. (1978). Mind and society. Cambridge, MA: Harvard University Press.

Wright, W. E., \& Choi, D. (2006). The impact of language and high-stakes testing policies on elementary school English language learners in Arizona. Education Policy Analysis Archives, 14(13), 1-55.

Xu, Y., \& Drame, E. (2008). Culturally appropriate context: Unlocking the potential of Response to Intervention for English language learners. Early Childhood Education, 35, 305-311.

Zehler, A. M., Fleischman, H. L., Hopstock, P. J., Stephenson, T. G., Pendzick, M. L., \& Sapru, S. (2003). Descriptive study of services to LEP students and LEP students with disabilities. Arlington, VA: U.S. Department of Education, Office of English Language Acquisition, Language Enhancement, and Academic Achievement of Limited English Proficient Students.

\section{Author Contact}

Emily Ferlis: erlisec@vcu.edu

Virginia Commonwealth University, 907 Floyd Ave, Richmond, VA 23284

Yaoying Xu: yxu2@vcu.edu

Virginia Commonwealth University, 907 Floyd Ave, Richmond, VA 23284 